\title{
Video Conferencing Solution for Synchronous Follow-Up of Cloud-Based IT Practical Work
}

\author{
https://doi.org/10.3991/ijoe.v16i14.17045 \\ Lamine Yade, Amadou Dahirou Gueye ( $\left.{ }^{\bowtie}\right)$, Bounama Gueye \\ Alioune Diop University, Bambey, Senegal \\ dahirou. gueyeduadb.edu.sn \\ Claude Lishou \\ Cheikh Anta Diop University, Dakar, Senegal
}

\begin{abstract}
In a difficult economic context in the world in general and in the countries of sub-Saharan Africa in particular where we seek to make maximum return on investments; this paper draws on part of cloud computing technologies to offer traditional universities the possibility of carrying out practical work via the cloud without using either physical IT equipment or physical practical rooms; and on the other hand, on videoconferencing technologies to ensure synchronous monitoring of this practical work. Thus, a cloud-based laboratory model for STEM disciplines is proposed in [1]. In the implementation of the model, we proposed the solution based on practical work in the field of IT. This paper document is an extension of [1] and offers a videoconferencing solution for monitoring practical work applied on the cloud for collaborative work between the teacher and the learners. In this new model, practical work is done using virtual machines from the cloud, but real-time monitoring is provided by a videoconferencing system, the following functionalities of which have been added: screen sharing, file sharing and virtual classroom recording.
\end{abstract}

Keywords - Classical University, Virtual laboratory; Practical work in IT, Cloud computing, videoconferencing, Synchronous Monitoring

\section{Introduction}

The global context of higher education is marked by a considerable increase in the number of students in sub-Saharan countries and international student flows. The major universities are unanimously engaged in the competition to capture these flows. They are more than ever the driving force of so-called knowledge societies and a special emphasis is placed worldwide on the development of STEM (Science, Technology, Engineering and Mathematics). Science education is above all, manipulation, experimentation and practical work.

However, universities find it difficult to keep up with the pace of supply and maintenance of existing infrastructure, given the growing number of students each year and 
the increasingly rapid pace of technological development which requires frequent updating of instruments, be they Scientific or industrial as well as software ones.

Thus, faced with the difficulties of supplying infrastructures to universities in developing countries, Cloud computing becomes an ideal solution for optimizing the resources of higher education and research [2]. This avoids investing heavily in infrastructure.

In addition, distance education has experienced rapid growth in recent years, offering the best courses from the best universities to a considerable mass of students around the world. The integration of distance education into Senegalese universities not only solves the problem of the mass enrollment of students but also problems such as the liberation of classrooms. This leads respectively to the creation of the virtual university of Senegal [3] and the creation of Open Distance Training FOAD in public universities. Alioune Diop University through its IFOAD has proposed a model for pooling transversal language teaching for the optimization of material, software and human resources [4]. However, the option of distance education encounters difficulties in carrying out practical work in technical scientific disciplines. Distance learning platforms such as Moodle [5] do not currently integrate practical work environments for these disciplines.

So, this paper proposes to set up a videoconferencing solution for monitoring practical work in cloud computing and collaborative work. To carry out our work, the rest of the paper will be organized as follows: In section 2, we present the state of the art of distance education and cloud computing as well as the research results in relationship with these two areas. In section 3, we present the architecture of our practical work model as well as how it works. In section 4, we propose a videoconferencing model coupled with a web platform and a Cloud environment. In section 5, we will present the results and the use case.

\section{State of the Art in Distance Education and the Cloud}

\subsection{Distance education}

Distance education today constitutes a major educational innovation and makes it possible to resolve not only the problem of the massification of baccalaureate holders and the professionalization of training but also and above all the optimization of educational and human resources [5]. This type of education is based on digital platforms that contain educational resources.

Today, with the development of modern means of communication (internet, mobile telephony, pocket computers), conventional universities integrating Open and Distance Learning (FOAD) and those that must respond to the challenges of distance, isolation or geographic distance separating the different actors [6] [7]. We realize today that Open and Distance Learning (FOAD) which recently interested professionals who wanted to complete their training, welcomes young people as soon as they obtain the baccalaureate between 18 and 20 years old, this is the case of Virtual University of Senegal (UVS) [2]. These young people need to be well trained in the fields, among 
others, of communication and STEM [9]. To do this, many existing distance learning platforms integrate self-assessment tools and online evaluation [10]. This is the case with Moodle which is used by many universities [4].

In addition, we also realize that Google and open fire use the Real-Time Communication Web API (WebRTC) to offer tools allowing communication in real time from browsers [11]. However, these tools and technologies offered in distance learning platforms do not make it possible to carry out practical work in IT, for example network practical work or online programming practical work. For this reason, we plan to use the cloud to get closer to practical work environments accessible via the web. These lab environments are done more flexibly from the cloud via virtual machines.

\subsection{Cloud computing}

The term Cloud Computing refers to IT services and resources provided on demand over the Internet [12]. In other words, it makes it possible to offer, via a telecommunications network, simple access anywhere, on demand and in self-service, to a set of configurable and shared IT resources: networks, servers, storage, applications and services. This paradigm revolutionizes the way universities manage their resources, leading to considerable budgetary savings.

With the introduction of Cloud Computing technologies, more and more laboratories are moved to the Cloud, known as virtual laboratories or Labs, in order to benefit from the advantages offered by Cloud Computing whether private or public, such as: flexibility, elasticity, resource sharing, reduction of the cost of administration, availability, business continuity, etc.

In $[12,13]$, the authors deal with the establishment, migration of virtual laboratories and online laboratories based on Cloud Computing. In [13], they propose a traditional laboratory migration framework in an open source cloud to have a dynamic, flexible, elastic, reliable laboratory called "Lab as a Service" principle. In [12] the virtual laboratory or Virtual Laboratories as a Service (VLaaS) is composed of virtual machine (hardware resources), operating system (OS) and application and the required files (software resources).

Thus, in [14] [15] [16] authors have proposed cloud laboratory solutions. In this paper, we focus on practical work solutions in computer science with the monitoring.

\section{Proposed Model of Cloud Based Laboratories Coupled with A Video Conference Solution}

Our cloud is organized in multi-tenant or multi-project, that is to say each tenant gathers a set of users of the same category, each category symbolizes a domain of STEM. The proposed model consists of a web platform, a cloud server and a videoconferencing server. The web platform serves as an interface for accessing virtual machines hosted in the cloud. It also serves as an interface to access video conferencing resources. The videoconferencing platform offers the functionality of screen sharing, file sharing and recording in a synchronous TP session. 
Figure 1 illustrates the laboratory model.

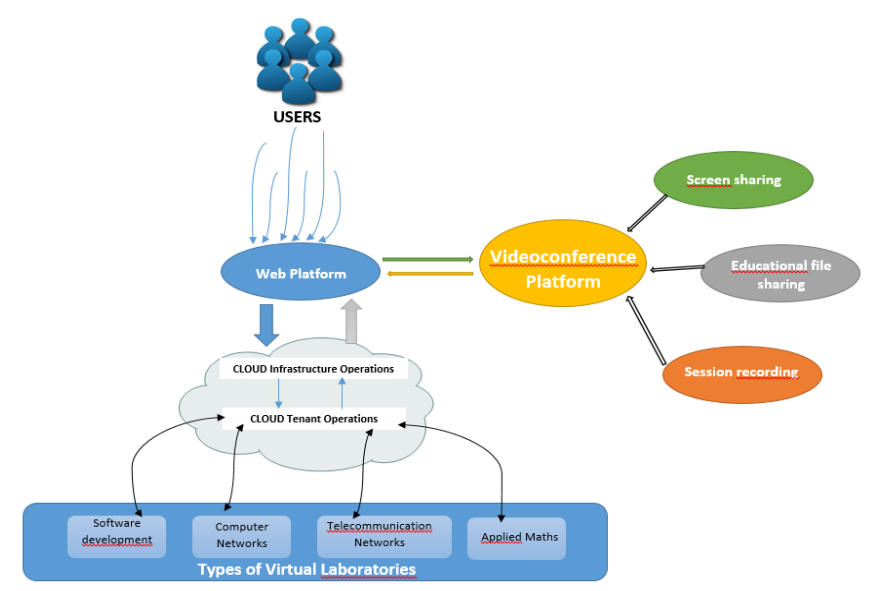

Fig. 1. Cloud-based laboratory model integrating videoconferencing

Figure 2 details the different processes of setting up practical work in an asynchronous session, from the resource request to the release of the resource.

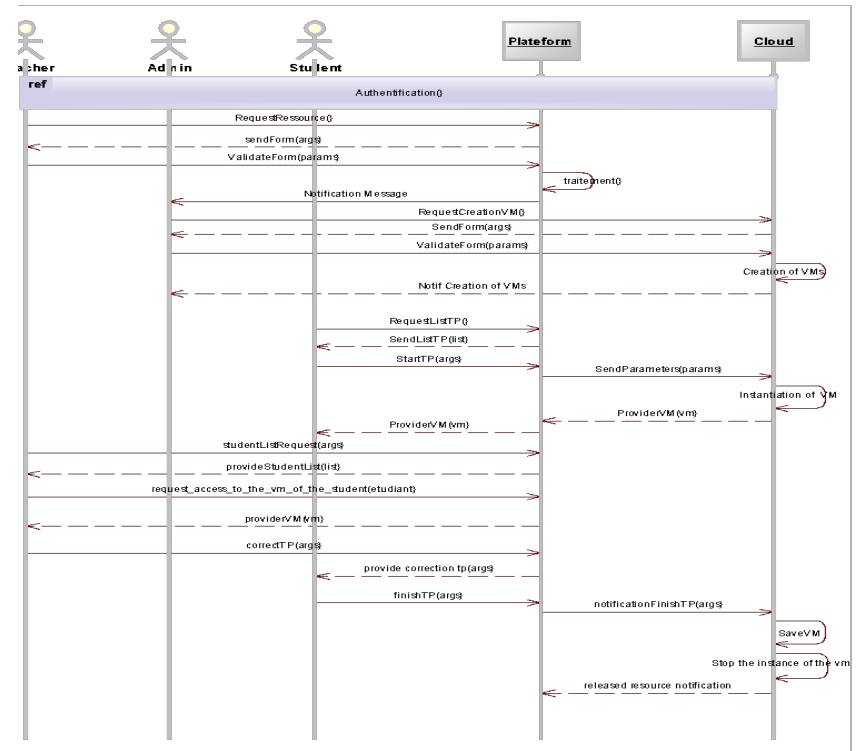

Fig. 2. Process of setting up a practical work

After the step of the process of setting up an asynchronous lab, we present in the following the process of follow-up by videoconference of practical work based on the cloud. 
The process follows these steps:

1. The teacher Invites students to a correction of synchronous practical work.

2. Start of the videoconference by the teacher or by the student.

3. The teacher chooses the screen sharing functionality and gives a demonstration of practical work visible to all.

4. Teacher can share documents.

5. The teacher can record the session.

6. The teacher can hand over to a student who will do the same.

Figure 3 illustrates such a process:

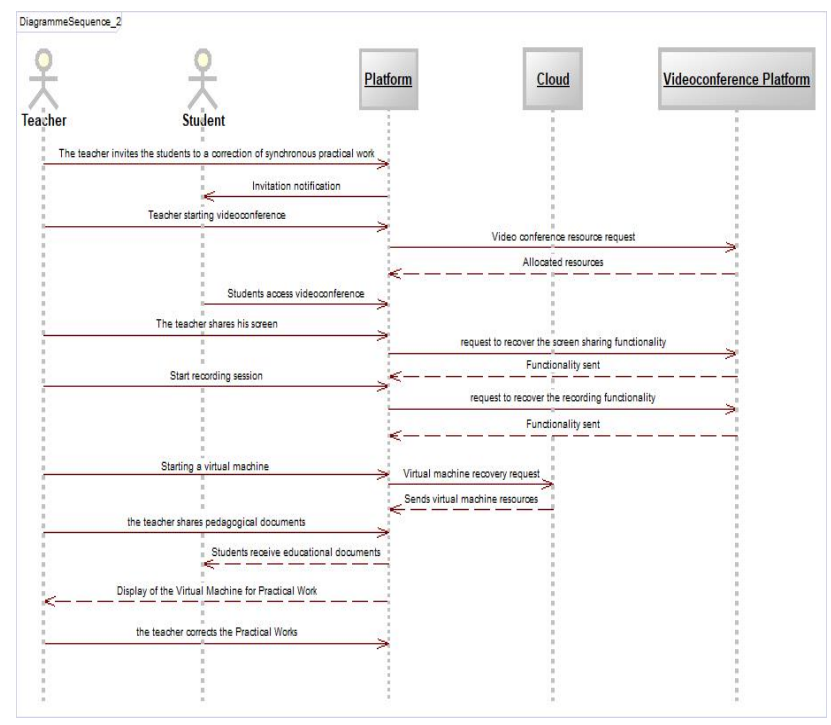

Fig. 3. Follow-up process of a synchronous practical work

\subsection{Network architecture of the system}

Our system is essentially composed of a virtual environment, a web application and the users whose different interactions are studied previously. 


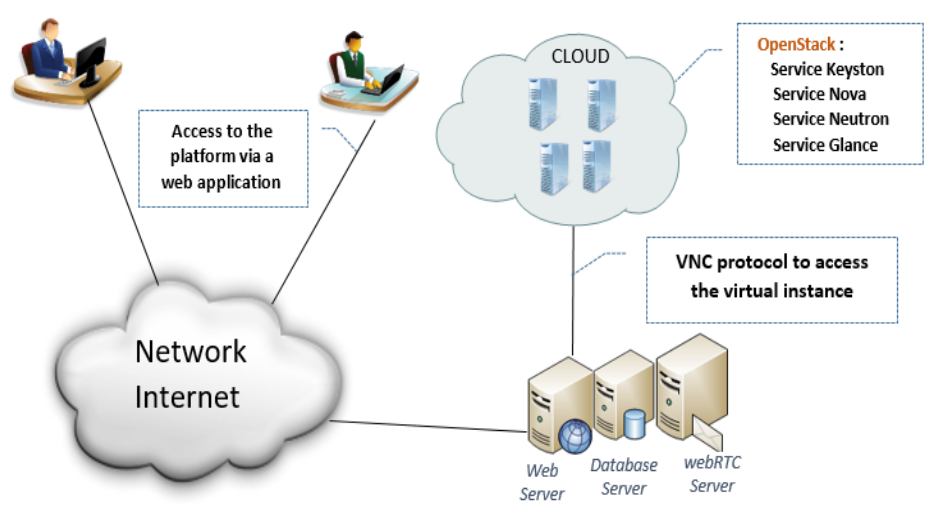

Fig. 4. Network architecture

\subsection{Features}

Figure 5 illustrates the different actors as well as the corresponding use cases.

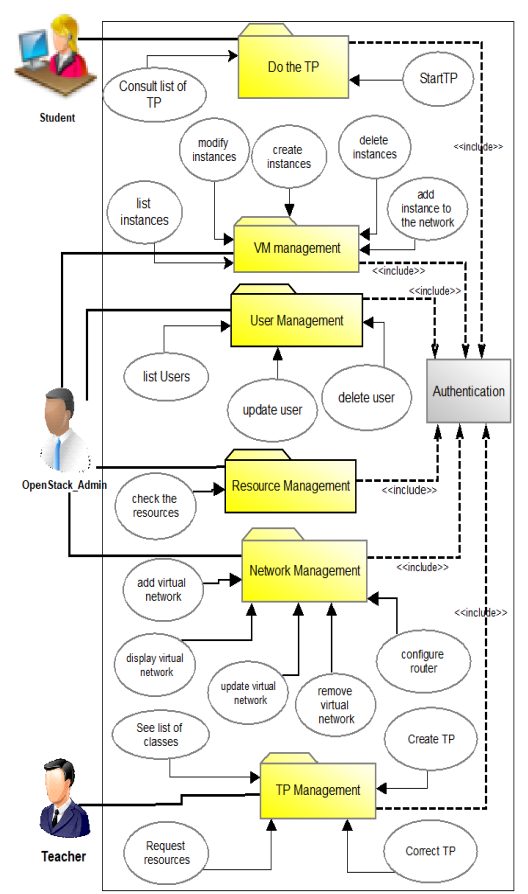

Fig. 5. Use case diagram 


\section{$4 \quad$ Results}

This work allowed us first to set up an IaaS (Infrastructure as a service) cloud infrastructure with open stack. Then, to manage users and labs, we implemented a platform accessible via a thin client. To apply the proposed model, we chose a type of lab in computer science dealing with python programming.

To access these instances and videoconferencing resources, we have developed a web platform to allow students to carry out practical work and teachers to prepare tutorials which they can monitor and supervise.

Figure 6 shows the authentication interface to the web platform.

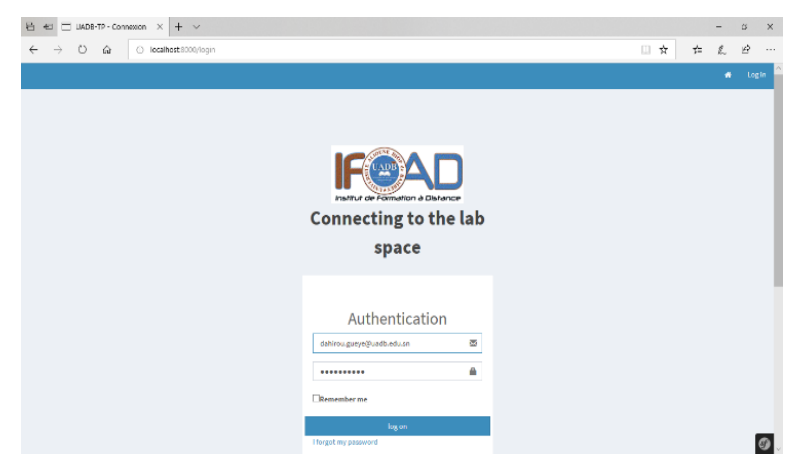

Fig. 6. Interface authentication to web platform

After authentication of the teacher, he joins a virtual class to be able to access the different functions of videoconferencing. The latter has the possibility to share screen, files, audio and camera with the students.

Figure. 7 shows the functionalities offered by videoconferencing.

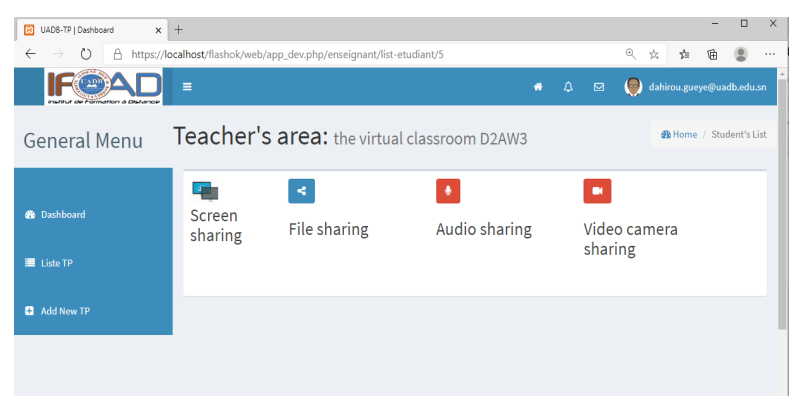

Fig. 7. Features of videoconferencing

Figure 8 shows an interface inviting the teacher to choose the tab to share with the students. 


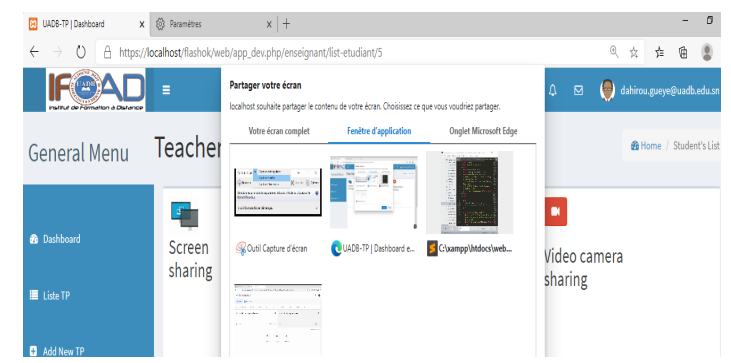

Fig. 8. Choose the lab to share

The student can now see the part of the screen that the teacher has shared, shown in Figure 9.

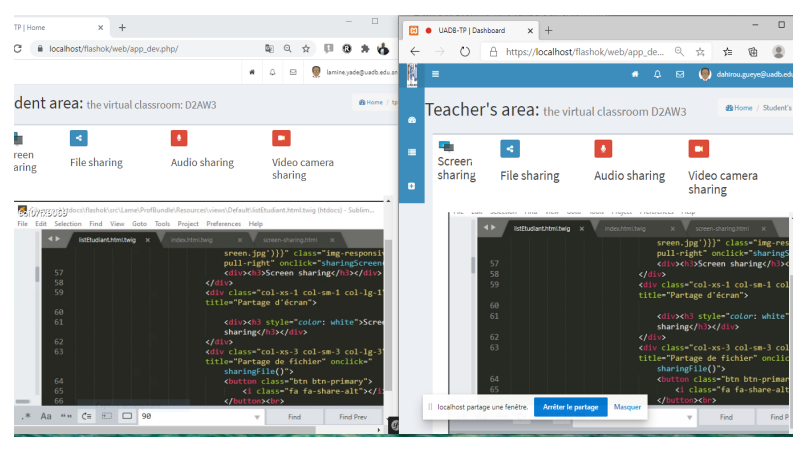

Fig. 9. Screen sharing between teacher and students

Figure 10 shows the teacher and student interfaces that send and receive files from both sides.

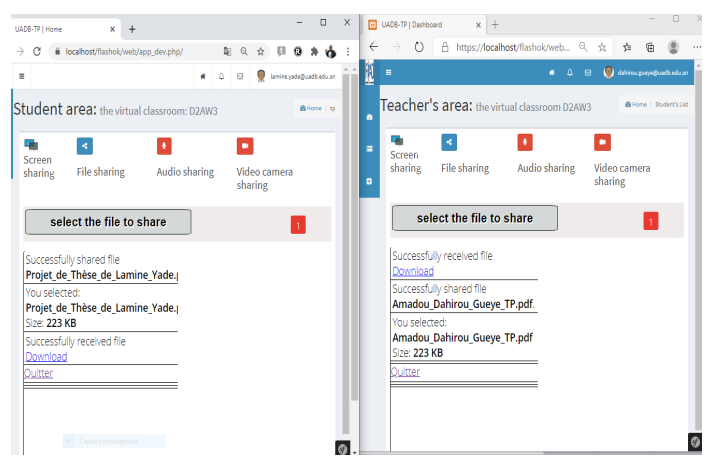

Fig. 10.Two-way file sharing interface

The student can also share his screen with the teacher for the purposes of correction or unblocking in relation to practical work. The interface in Figure 11 illustrates the 
possibility for a student to share his practical work terminal with a teacher or all the students in the class.

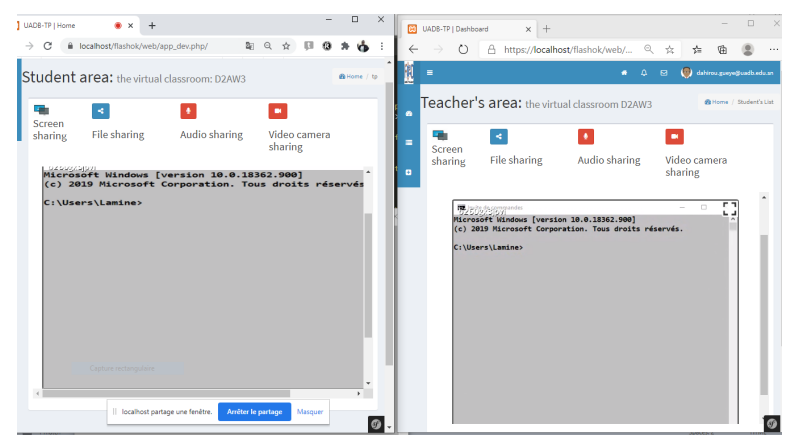

Fig. 11.Screen sharing by a student

The teacher can edit a Practical work by giving the instructions via this interface which will be visible afterwards to the students.

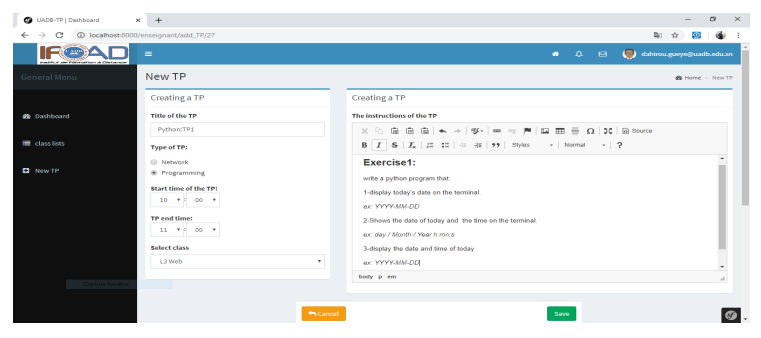

Fig. 12. Teacher practical works editing interface

The student will have on his dashboard the list of practical works concerning him. On each of them, we specified the dates as well as the start and end times.

Figure. 13 illustrates such a scenario.

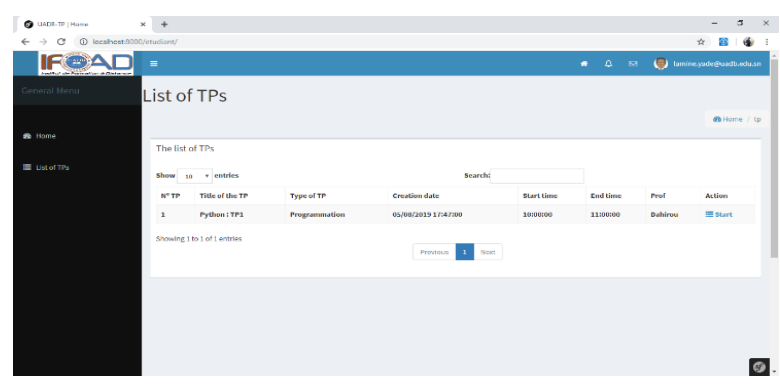

Fig. 13.List of practical works for a student

Afterwards, the student can choose from the list a practical work to be done by clicking on start. After that, he will have a single interface on the left with the instructions 
related to the Practical work (PW) and on the right, the virtual machine where he will have to execute the (PW) instructions.

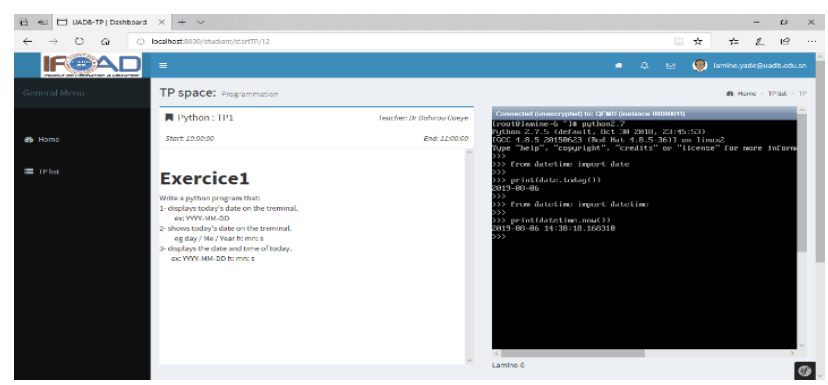

Fig. 14. Interface for carrying out a practical work

\section{Conclusion}

In this paper, we first started with a cloud-based lab laboratory model and then integrated a videoconferencing solution for synchronous monitoring of these labs. The teacher can in the middle of practical work activate his audio to speak with the learners, or share his screen with the learners or send files. The practical work is done from virtual machines hosted in the cloud that we have set up. Access to virtual cloud resources or video conferencing functionality is effective by a web platform that we have developed and that serves as an interface.

In perspective, we plan to host the videoconferencing solution in a cloud computing server shared in the medium term between the public universities of Senegal and in the long term between the universities of Sub-Saharan Africa. Covid-19 showed that several of the distance learning platforms of several universities presented limits in the management of virtual classes. Thus, a shared video conferencing solution between developing universities would bring many advantages.

\section{References}

[1] Amadou Dahirou Gueye; Lamine Yade; Bounama Gueye; Omar Kasse; Claude Lishou (2020). Cloud and WebRTC based Laboratory Solution for Practical Work in Computer Science for a Traditional University. Published in: 2020 IEEE Global Engineering Education Conference (EDUCON), Conference Location: Porto, Portugal, Portugal 27-30 April 2020, Date Added to IEEE Xplore: 25 June 2020, Electronic ISBN: 978-1-7281-0930-5, https://doi.org/10.1109/educon45650.2020.9125201

[2] Amadou Dahirou Gueye, Ibrahima Sanogo, Samuel Ouya, Hamadou Saliah-Hassane, Claude Lishou, (2014), "Proposal a Cloud Computing Solution and Application in a Pedagogical Virtual Organization", In Proceedings of the INEER ICEE/ICIT Joint International Conference on Engineering Education and the International conference on Information 
Technology, ICEE/ICIT2014, ISBN: 978-9934-10-560-9, pp. 349-358, Riga, Latvia 2014. https://doi.org/10.1109/icl.2014.7017848

[3] UVS, "Université Virtuelle du Senegal," 2015. [Online]. Available: http://www.uvs.sn/.

[4] Gueye A.D., Mballo M.H.W., Kasse O., Gueye B., Ba M.L. (2019) Model of Integration of Distance Education in a Traditional University: Migration of Cross-Cutting Courses to Distance Learning. In: Auer M., Tsiatsos T. (eds) The Challenges of the Digital Transformation in Education. ICL 2018. Advances in Intelligent Systems and Computing, vol 917. Springer, Cham. Print ISBN: 978-3-030-11934-8, Online ISBN 978-3-030-11935-5 https://doi.org/10.1007/978-3-030-11935-5 2

[5] Moodle, 2019 [Online]. Available: https://moodle.org/.

[6] Bounama Gueye, Amadou Dahirou Gueye, Assane Gueye, Oumar Kassé and Claude Lishou, Proposal of an intelligent remote tutoring model, Proceedings IMCL 2019, Grece, 30 oct 01 Nov 2019. https://doi.org/10.1007/978-3-030-49932-7_29

[7] Alloys MBALA HIKOLO, “Analyze, conception, specification et development d'un system multi-agents pour le soutien des activities en formation à distance", these University de Franche Comté, soutenue le 16 October 2003.

[8] Kukeneh, S.S.; Shahbahrami, A.; Mahdavi, M., "Personalized virtual university: Applying personalization in virtual university," Artificial Intelligence, Management Science and Electronic Commerce (AIMSEC), 2011 2nd International Conference on, vol., no., pp.6704,6706, 8-10 Aug. 2011. https://doi.org/10.1109/aimsec.2011.6011232

[9] Nite, S.B.; Margaret, M.; Capraro, R.M.; Morgan, J.; Peterson, C.A., "Science, technology, engineering and mathematics (STEM) education: A longitudinal examination of secondary school intervention, "Frontiers in Education Conference (FIE), 2014 IEEE, vol., no., pp.1,7, 22-25 Oct. 2014. https://doi.org/10.1109/fie.2014.7044214

[10] Aydin, C.C.; Tirkes, G., "Open source learning management systems in e-learning and Moodle," Education Engineering (EDUCON), 2010 IEEE, vol., no., pp.593,600, 14-16 April 2010. https://doi.org/10.1109/educon.2010.5492522

[11] Salvatore Loreto, Simon Pietro Romano, Real-Time Communication with WebRTC, Publisher(s): O'Reilly Media, Inc., ISBN: 978-1-449-37187-6, Released May 2014.

[12] M. Blas, "Teresa and Serrano-Fernández, The role of new technologies in the learning process: Moodle as a teaching tool in Physics," Ana Computers and Education, vol. 3, pp.3544, March 2009. https://doi.org/10.1016/j.compedu.2008.06.005

[13] LLC Cloud Strategy Partners, Cloud Computing Definition, Reference Architecture, and General Use Cases, Publisher: IEEE, Year: 2014

[14] Ibrahima Sanogo; Samuel Ouya; Amadou Dahirou; Claude Lishou, Proposal of cloud-based online laboratory model for practical training in the telecoms and networking fields, 2016 IEEE Global Engineering Education Conference (EDUCON), Publisher: IEEE, Year: 2016. https://doi.org/10.1109/educon.2016.7474691

[15] Davy Edgard Moussavou; Samuel Ouya; Pape Djidiack Faye; Mary Teuw Niane; Claude Lishou.

[16] Remote laboratory experience for STEM education: The case of Senegal Virtual University, 2015 International Conference on Interactive Collaborative Learning (ICL), Publisher: IEEE, Year: 2015. 


\section{Authors}

Lamine Yade works at ICT, Alioune Diop University, Bambey, Senegal. Email: lamine.yade@uadb.edu.sn

Amadou Dahirou Gueye works at ICT, Alioune Diop University, Bambey, Senegal. Email: dahirou.gueye@uadb.edu.sn

Bounama Gueye works at ICT, Alioune Diop University, Bambey, Senegal. Email: Bounama.gueye@uadb.edu.sn

Claude Lishouesp works at Cheikh Anta Diop University, Dakar, Senegal. Email: clishou@ucad.sn

Article submitted 2020-07-14. Resubmitted 2020-09-10. Final acceptance 2020-09-10. Final version published as submitted by the authors. 